\title{
Changes in the epidemiology and management of bacterial infections in cirrhosis
}

\author{
Salvatore Piano, Marta Tonon, and Paolo Angeli \\ Unit of Internal Medicine and Hepatology, Department of Medicine, University of Padova, Padova, Italy
}

Patients with cirrhosis are susceptible to develop infections because of immune dysfunction, changes in microbiome and increase in bacterial translocation from the gut to systemic circulation. Bacterial infections can worse the clinical course of the disease, triggering the development of complications such as acute kidney injury, hepatic encephalopathy, organ failures and acute on chronic liver failure. In recent years, the spread of multi drug resistant bacteria made more challenging the management of infections in patients with cirrhosis. Hence, the mortality rate associated to sepsis is increasing in these patients. Therefore, the optimization of the management of infections has a high priority in cirrhosis. Herein we reviewed the recent changes in the epidemiology and the management of bacterial infections in patients with liver cirrhosis. (Clin Mol Hepatol 2021;27:437-445)

Keywords: Sepsis; Liver transplantation; Septic shock; Antimicrobial stewardship

\section{INTRODUCTION}

Patients with liver cirrhosis are more susceptible to develop bacterial infections than the general population. This is due to several factors that predispose to the occurrence of overt infections.

Firstly, patients with cirrhosis frequently show a certain degree of acquired immunodeficiency which has been termed "cirrhosisassociated immune dysfunction". ${ }^{2}$ Several mechanisms contribute to immune dysfunction, such as the reduction of leukocytes count due to hypersplenism, the reduced production of innate immunity proteins (such as complement), the exhaustion of immune cells, the impairment in neutrophils' phagocytosis and oxidative burst, the release of anti-inflammatory cytokines and the hyperactiva- tion of tryptophan-kynurenine pathway. ${ }^{2,3}$ Moreover, portal hypertension induces a disruption of intestinal barrier causing an increase in intestinal permeability that eases the translocation of intestinal bacteria from the gut to the bloodstream. ${ }^{4}$ The bacterial translocation is facilitated by the intestinal bacterial overgrowth and the relative changes in microbiome species (dysbiosis), with a reduction of beneficial phyla and an increase on pathogenic phyla (such as Enterobacteriaceae and Enterococcaceae). ${ }^{4,5}$ All these factors make the patients with cirrhosis susceptible to the development of infections, which are associated with the onset of complications such as acute kidney injury (AKI), hepatic encephalopathy, organ failures and increase 4 -fold the mortality risk. ${ }^{6-9}$ Indeed, infections are the most common precipitating event of an acute decompensation of cirrhosis and are associated with a se-

\footnotetext{
Abbreviations:

ACLF, acute-on-chronic liver failure; AKI, acute kidney injury; CA, community acquired; GI, gastrointestinal; MDR, multidrug-resistant; MIC, minimal inhibitory concentration; RAI, relative adrenal insufficiency; SBP, spontaneous bacterial peritonitis; SSTIs, skin and soft tissues infections; UTIs, urinary tract infections; $\mathrm{XDR}$, extensively drug resistant
}

\section{Corresponding author: Salvatore Piano}

Unit of Internal Medicine and Hepatology, Department of Medicine, University of Padova, Via Giustiniani 2, Padova 35100, Italy

Tel: +39/0498212265, Fax: +39/0498218676

E-mail: salvatorepiano@gmail.com

https://orcid.org/0000-0002-9356-5830 
vere clinical course..$^{10}$ Remarkably, the risk of dying because of sepsis is currently increasing in patients with cirrhosis, ${ }^{11}$ probably because of the increasing spread of multidrug-resistant (MDR) bacteria and the lack of new effective antibiotics. ${ }^{12}$

For all these reasons, infections in cirrhosis are a very hot topic that needs to be carefully considered by clinicians. Herein we concisely reviewed the current changes in the epidemiology and management of bacterial infections in patients with cirrhosis.

\section{EPIDEMIOLOGY OF BACTERIAL INFECTIONS IN CIRRHOSIS}

\section{Prevalence and characteristics of infections}

The prevalence of bacterial infections is about $25-46 \%$ in cirrhotic patients hospitalized for an acute decompensation of cirrhosis. ${ }^{13,14}$ In about two third of cases, infections are diagnosed at admission, either community acquired (CA) (30-50\%) or healthcare-associated (i.e., occurring in patients hospitalized in the prior 3 months, living in nursing home residency or requiring intravascular therapy; $25-40 \%$ ), whereas one third of patients develops nosocomial infections. ${ }^{13,15-21}$ Patients with severe liver dysfunction (higher MELD score and Child-Pugh score), with ascites and low protein concentration in ascitic fluid or with gastrointestinal (GI) bleeding are at higher risk of developing infections. ${ }^{1}$

Several prospective studies have shown that spontaneous bacterial peritonitis (SBP) is the most common infection in patients with cirrhosis, accounting for $20-30 \%$ of infections in these patients. Other common infections are urinary tract infections (UTIs; 20-25\%), pneumonia (20\%), spontaneous bloodstream infections $(8-15 \%)$ and skin and soft tissues infections (SSTIs; 5-10\%). 13,15,16,21 About $20 \%$ of patients with infections develop second infections during the hospitalization, which are associated with a further increase in mortality risk. ${ }^{21}$

As for the type of bacteria involved, Enterobacteriaceae (such as Escherichia coli and Klebsiella pneumoniae) and other gram negative bacteria are the most common bacteria involved in the development of SBP and UTIs (accounting for $50-70 \%$ of cases), whereas gram positive bacteria such as Staphylococcus aureus and Enterococci accounts for $30-45 \%$ of cases. ${ }^{15,22,23}$ In patients with pneumonia and SSTIs gram-positive bacteria prevails. ${ }^{15} \mathrm{~A}$ certain proportion of the aforementioned bacteria are MDR (i.e., bacteria resistant to at least one antibiotic in at least three antimicrobial categories) or extensively drug resistant (XDR; i.e., resis- tant to at least one agent in all but less than two antimicrobial categories). The most common type of MDR bacteria in cirrhosis are extended spectrum beta lactamase and AmpC- producing Enterobacteriaceae, methicillin resistant Staphylococcus aureus and vancomycin resistant enterococci. ${ }^{13,15,16}$ The most common XDR bacteria are carbapenemase producing enterobacteriaceae, carbapenem resistant Pseudomonas aeruginosa and Acinetobacter baumannii. ${ }^{15}$

\section{The recent changes in the epidemiology of infections and the issue of multi-drug resistant bacteria}

In the last two decades three relevant epidemiological changes occurred in patients with cirrhosis and bacterial infections. First of all, the implementation of the use of quinolones for the prophylaxis of bacterial infections led to an increase in infections due to gram-positive bacteria. ${ }^{24}$ Secondly, the wide use of third generation cephalosporins led to an increase of infections due to enterococci (constitutively resistant to cephalosporins), in particular in healthcare-associated and nosocomial infections. . $^{13,15,23,25}$ The last and most important change was the increase in the prevalence of MDR bacteria and XDR bacteria. Fernández et al. ${ }^{16,24}$ showed that in their center the prevalence of MDR organisms was less than $10 \%$ at the end of ' 90 s and increased to $23 \%$ in 2012 . More recently a large European multicenter study showed an increase in the prevalence of MDR organisms from 29\% to 38\% from 2011 to $2017-2018 .^{13} \mathrm{~A}$ multicenter intercontinental study including more than 1,300 patients with cirrhosis showed a prevalence of MDR bacteria of $34 \%$ in culture positive infections, with a relevant heterogeneity among different geographic areas, ranging from less than $20 \%$ in USA to more than $70 \%$ in India. ${ }^{15}$ The prevalence of XDR organisms showed a similar heterogeneity ranging from $0 \%$ in Canada and Switzerland to $33 \%$ in India. ${ }^{15}$ Similar heterogeneity was also observed in other multicenter and single center studies (Fig. 1). These findings suggest that physicians caring for patients with cirrhosis and infections should interact with microbiologist to know the local epidemiology and prevalence of MDR bacteria at their institution.

The increase in MDR and XDR bacteria represents an important challenge in the management of infections in patient with cirrhosis, because infections caused by these germs are more difficult to be treated and are associated to an increased risk of failure of antibiotic treatment, development of septic shock and in-hospital mortality. 12,13,15,16,23 Several studies identified risk factors for the development of MDR bacteria, such as an antibiotic course with 


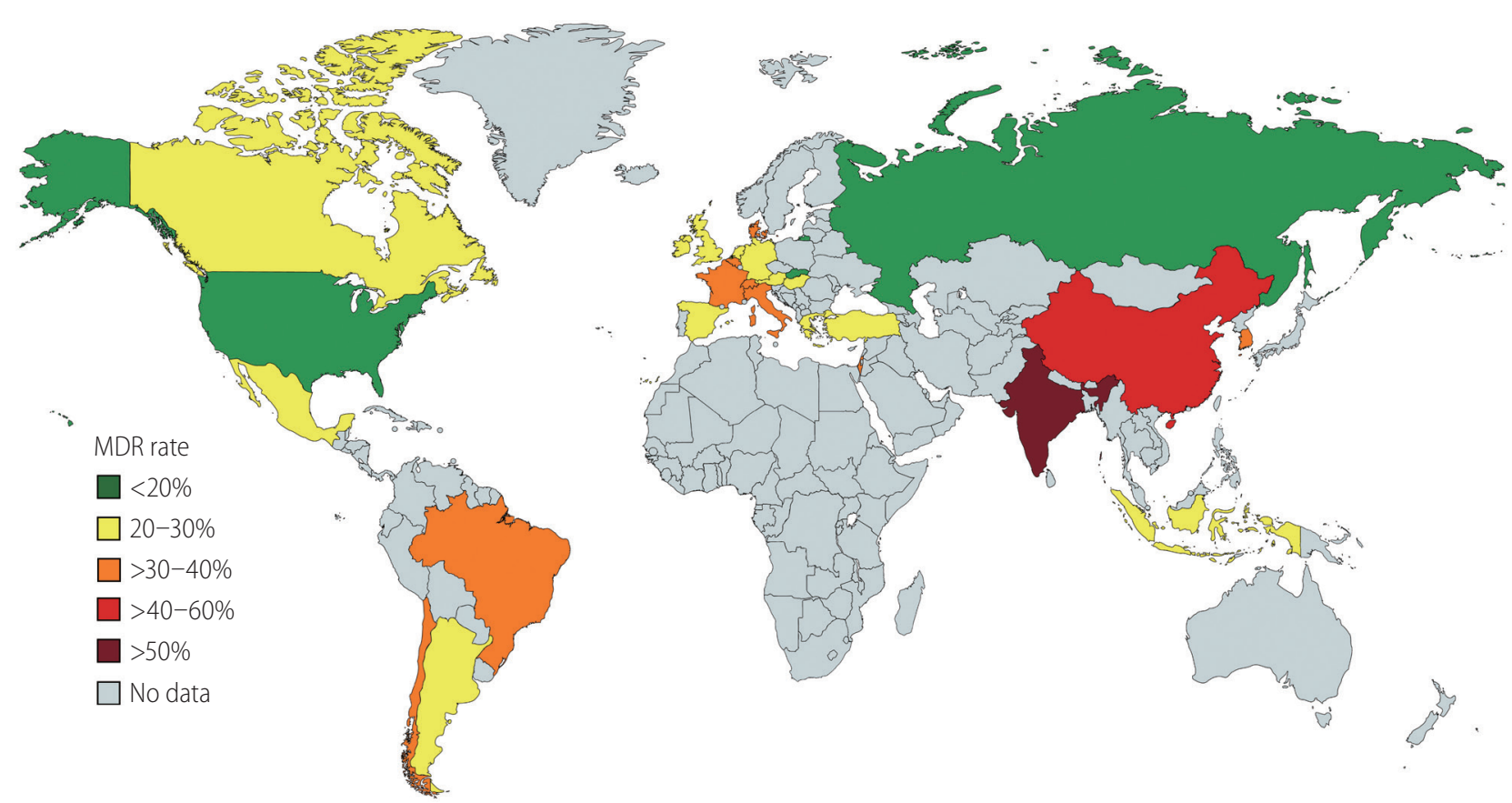

Figure 1. Prevalence of multidrug-resistant (MDR) bacteria in patients with cirrhosis across the world. Different colors represent different rates of prevalence of MDR.

beta-lactams or other antibiotics in the prior 3 months, a hospitalization in the 3 months prior, invasive procedures and nosocomial infections. ${ }^{13,15,16,19,20,23}$

\section{MANAGEMENT OF BACTERIAL INFECTIONS}

\section{General management}

The first measure to promptly identify and treat infections in patients with cirrhosis is to look for them. This could seem an obvious concept, but certainly not to be underestimated, considering that typical signs of infection (like fever) may not be present in the early phases in these patients. ${ }^{26}$

The onset of complications of cirrhosis, such as occurrence or worsening of ascites, hepatic encephalopathy or GI bleeding or worsening of renal function can be the first manifestation of an ongoing infection. Therefore, an adequate work up for infections (e.g., diagnostic paracentesis, chest X-ray, urinalysis, blood, ascites and urine cultures) should be made in all patients hospitalized for decompensated liver disease (Fig. 2). ${ }^{27}$ In addition, patients that are at a high risk of infections (and especially of MDR infection) should be monitored closely.
Bacterial infections can often cause organ dysfunctions, which are the hallmark of sepsis and are associated with a high risk of death. ${ }^{18}$ The onset of organ failures is associated with a further decrease in survival rate..$^{18,28,29}$ The onset of organ failures in patients with cirrhosis characterize a syndrome named acute-onchronic liver failure (ACLF), ${ }^{30}$ for which bacterial infections are the most common trigger and associated with a lower survival. ${ }^{31}$ Therefore, organ dysfunction/failures should be promptly evaluated in cirrhotic patients with infection. Assessment of liver, kidney, brain, coagulation, circulation and lung functions is fundamental in these patients and can be performed via the chronic liver failure consortium organ failure score scale and the consequent ACLF grade assessment. ${ }^{30}$

Among organs, the deterioration of renal function is frequent in cirrhotic patients with infection. ${ }^{32}$ Renal function should be closely monitored for an early diagnosis and treatment of AKI and for tailoring the doses of antibiotics to renal function. ${ }^{33}$

In order to prevent development of AKI, all potentially nephrotoxic drugs, such as non-steroidal anti-inflammatory drugs, vasodilators and aminoglycosides should be avoided in these patients. ${ }^{27}$ Beta-blockers should be used with caution and temporarily tapered/withdrawn in patients with hypotension (systolic blood pressure $<90 \mathrm{mmHg}$ and/or AKI). ${ }^{27}$ 


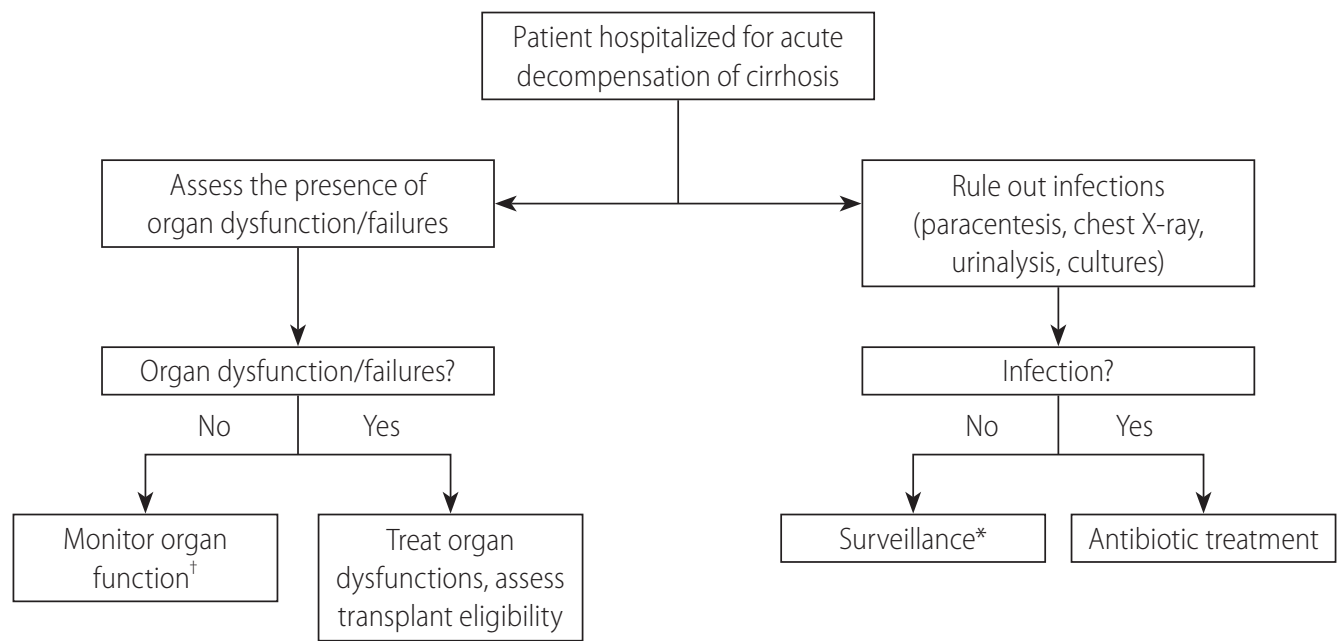

Figure 2. Approach for the early diagnosis of infections in patients with cirrhosis. *Repeat work-up for infections in case of worsening of liver/renal function and/or development of further complications/organ failures. ${ }^{\dagger}$ Control renal and liver function at least every 48 hours.

\section{Antibiotic treatment}

Empirical antibiotic treatment should be started as soon as possible in patients with cirrhosis and bacterial infections. ${ }^{1,27}$ In fact, a delayed antibiotic treatment is associated with an increased risk of mortality, in particular in patients with septic shock. ${ }^{34}$ Empirical antibiotic treatment should virtually target all the bacteria potentially responsible for the infection, because an adequate empirical antibiotic treatment is associated with a reduction in mortality rate. ${ }^{13,15}$

Considering the aforementioned differences in the prevalence of MDR bacteria throughout the world, protocols of antibiotic treatment should be tailored to the local epidemiology. However, general suggestions/recommendations can be useful for developing such protocols. ${ }^{1,27}$

The empirical antibiotic of choice should be determined according to the following features: 1) the type and site of infection; 2) likelihood of MDR bacteria; 3) the severity of infection; 4) local epidemiology (Table 1). ${ }^{1,26}$ As previously mentioned, the drug of choice should be selected balancing the need of an agent effective on all potential bacteria responsible for the infection, but also the potential side effects and the risk of selecting MDR bacteria. ${ }^{12,26}$

As far as CA infections are concerned, third-generation cephalosporins are the drug of choice for treating empirically SBP, spontaneous bacterial empyema and spontaneous bloodstream infections. UTI can be treated with quinolones or cotrimoxazole; however, in complicated UTI third-generation cephalosporins or amoxicillin/clavulanic acid should be preferred. Pneumonia should be treated with the combination of third-generation cephalospo- rins or amoxicillin/clavulanic acid plus macrolides or respiratory quinolones (e.g., levofloxacin). In SSTIs third-generation cephalosporins or amoxicillin/clavulanic acid or oxacillin should be used.

In patients with nosocomial infections, a broader spectrum antibiotic treatment is needed because third generation cephalosporins, quinolones and amoxicillin/clavulanic acid are poorly effective in these patients. ${ }^{15,16,35}$ The antibiotic regimen for nosocomial UTI should be based on piperacillin/tazobactam or carbapenems. When considering nosocomial SBP, spontaneous bacterial empyema and spontaneous bloodstream infections, the use of piperacillin/tazobactam or carbapenems, with or without lypopeptides/ glycopeptides should be considered. ${ }^{35,36}$ The empirical use of carbapenems should be used only in centers with a high rate of MDR bacteria or in patients with organ failures, ${ }^{37}$ because it carries on the risk of further emergence of XDR bacteria. Nosocomial pneumonia should be treated with piperacillin/tazobactam or carbapenems plus a respiratory quinolone active against $P$ seudomonas. Nosocomial SSTIs should be treated with carbapenems or ceftazidime plus oxacillin. In any of these infections, glycopeptides, lypopeptides, linezolid and other possible options should be added according to the local prevalence of gram positive MDR bacteria. Health care-associated infections and infections occurring in patients with other risk factors (e.g., recent antibiotic course) constitutes a heterogeneous population. In centers with a high rate of MDR bacteria in these infections, a broad spectrum treatment (as for nosocomial infections) is associated with an improvement in survival. ${ }^{38}$

In patients at high risk of mortality such as those with sepsis, ACLF or septic shock patients should be aggressively treated with 
Table 1. Recommended empirical antibiotic treatment for bacterial infections in cirrhosis

\begin{tabular}{|c|c|c|}
\hline Type of infection & Community-acquired infections & Nosocomial infections* \\
\hline $\begin{array}{l}\text { SBP, SBE and spontaneous } \\
\text { bacteremia }\end{array}$ & $\begin{array}{l}\text { Cefotaxime or ceftriaxone or amoxicillin/clavulanic } \\
\text { acid }\end{array}$ & $\begin{array}{l}\text { Piperacillin/tazobactam }{ }^{\S} \text { or meropenem }{ }^{\dagger} \pm \text { glycopeptide }^{\ddagger} \\
\text { or daptomycin or linezolid }\end{array}$ \\
\hline UTI & $\begin{array}{l}\text { Uncomplicated: ciprofloxacin or cotrimoxazole } \\
\text { If sepsis: cefotaxime or ceftriaxone or amoxicillin/ } \\
\text { clavulanic acid }\end{array}$ & $\begin{array}{l}\text { Uncomplicated: nitrofurantoin or Fosfomycin } \\
\text { If sepsis: piperacillin/tazobactam }{ }^{\S} \text { or } \\
\text { meropenem } \pm \text { glycopeptide }\end{array}$ \\
\hline Pneumonia & $\begin{array}{l}\text { Amoxicillin/clavulanic acid or ceftriaxone+macrolide } \\
\text { or levofloxacin or moxifloxacin }\end{array}$ & $\begin{array}{l}\text { Piperacillin/tazobactam }{ }^{\S} \text { or meropenem/ceftazidime+cip } \\
\text { rofloxacin } \pm \text { glycopeptide } \text { or linezolid should be added } \\
\text { in patients with risk factors for MRSA }\end{array}$ \\
\hline Cellulitis & Amoxicillin/clavulanic acid or ceftriaxone+oxacillin & $\begin{array}{l}\text { Meropenem/ceftazidime+oxacillin or glycopeptides or } \\
\text { daptomycin or linezolid" }\end{array}$ \\
\hline
\end{tabular}

Modified from Piano et al. ${ }^{26}$ with permission.

SBP, spontaneous bacterial peritonitis; SBE, spontaneous bacterial empyema; UTI, urinary tract infection; MRSA, methicillin-resistant Staphylococcus aureus.

* Recommended empirical treatment also for health-care associate (HCA) urinary infections and pneumonia. Empirical antibiotic treatment of HCA spontaneous infections and cellulitis will be decided on the basis of the severity of infection (patients with severe sepsis should receive the schedule proposed for nosocomial infections) and on the local prevalence of multiresistant bacteria in HCA infections.

${ }^{\dagger}$ Ventilator-associated pneumonia, previous antibiotic therapy, nasal MRSA carriage.

${ }^{\ddagger}$ Among glycopeptides only IV vancomycin in areas with a high prevalence MRSA and vancomycin-susceptible enterococci. Vancomycin must be replaced by daptomycin or linezolid in areas with a high prevalence of vancomycin-resistant enterococci.

${ }^{\S}$ In areas with a low prevalence of multidrug-resistant bacteria.

"IV vancomycin or teicoplanin in areas with a high prevalence MRSA and vancomycin-susceptible enterococci. Vancomycin must be replaced by linezolid in areas with a high prevalence of vancomycin-resistant enterococci.

antibiotic schemes provided for nosocomial infections (Fig. 3). ${ }^{37}$ Indeed, in these patients, antibiotic treatment should not fail, because failure is associated with a surge in the risk of death. Betalactam use should be improved in these patients according to pharmacodynamic/pharmacokinetic considerations. In fact, considering that beta-lactams are time dependent antibiotics (i.e., the efficacy depends on the time the concentration is above the minimal inhibitory concentration [MIC]) and have short half-life, an extended/continuous infusion strategy can enhance the time above the MIC. Recently, this strategy was associated with improved survival in patients with cirrhosis and bloodstream infections. $^{39}$

In patients in whom a broad-spectrum antimicrobial treatment is initiated, the antibiotic treatment should be narrowed according to the results of microbiological cultures and antimicrobial susceptibility test. ${ }^{27}$ In patients with negative cultures the sequential use of biomarkers such as C-reactive protein or procalcitonin may be useful in assessing clinical response since these biomarkers decreases in patients under adequate treatment. ${ }^{40}$ That said, future studies should demonstrate whether a biomarker-driven antibiotic treatment is feasible in patients with cirrhosis. For patients with infections due to XDR bacteria, novel drugs active in carbapenem resistant enterobacteriaceae (ceftazidime/avibactam, meropenem/ varbobactam, cefiderocol), Pseudomonas aeruginosa (ceftolo- zane/tazobactam, ceftazidime/avibactam, cefiderocol) and Acinetobacter baumannii (cefiderocol) are currently available. Their empirical use should be reserved to patients colonized by XDR bacteria.

A correct duration of the antibiotic treatment has not been established, except for SBP, for which a 5-day course has been advised. ${ }^{41}$ For most of the other infections a 7-day course is sufficient.

\section{Non-antibiotic treatment}

The treatment of infections in cirrhosis also includes strategies to prevent AKI and organ failures. In patients with SBP, the use of human albumin at the dose of $1.5 \mathrm{~g} / \mathrm{kg}$ on day 1 and $1 \mathrm{~g} / \mathrm{kg}$ on day 3 reduces the incidence of AKI and improves survival. ${ }^{42}$ Clinical and experimental data suggest that the effects of albumin were not only related to its oncotic properties, but also to its antioxidant, scavenging and immunomodulatory activity. ${ }^{43}$ In non-SBP infections, three randomized trial were performed with controversial results. Guevara et al. ${ }^{44}$ found a reduced incidence of AKI and improved survival in patients treated with albumin, while Thévenot et al. ${ }^{45}$ did not find significant differences in survival in patients treated or not with albumin. More recently, Fernández et al ${ }^{46}$ showed no difference in mortality rate in albumin and control 


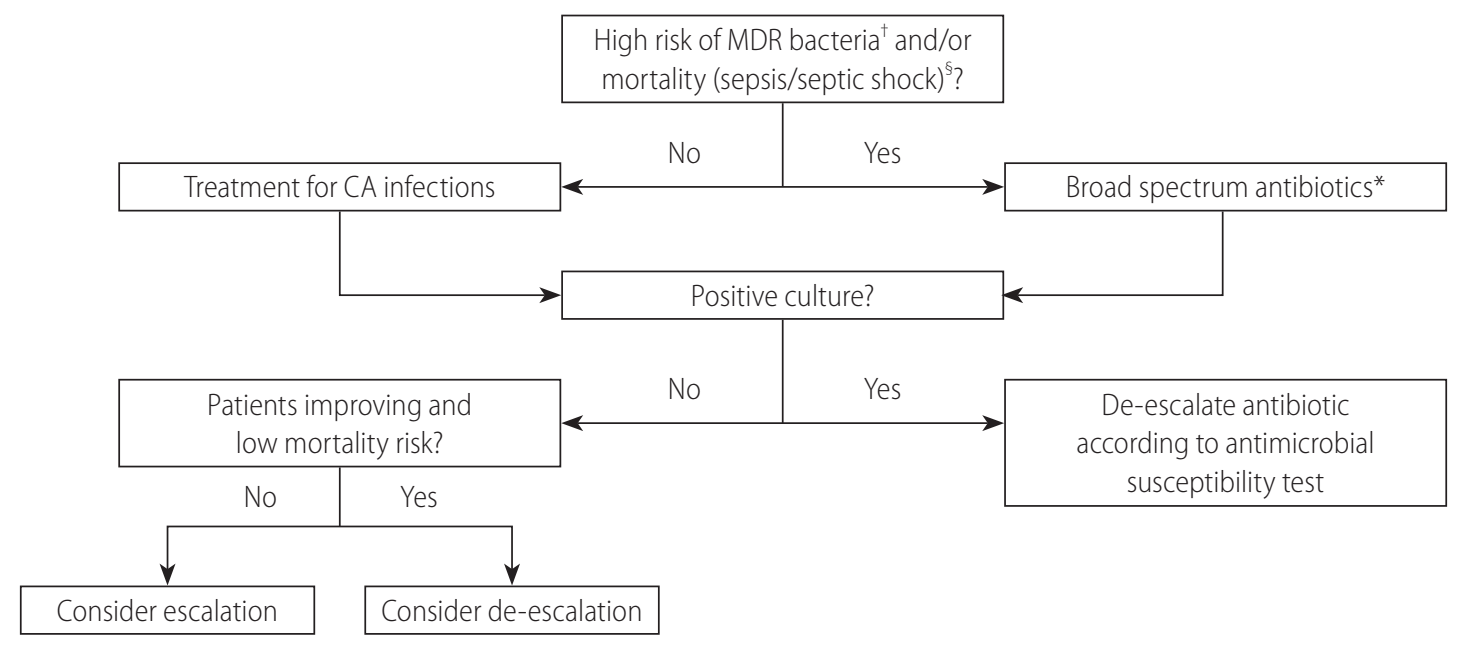

5-7-day treatment is sufficient for most infection $^{\ddagger}$

Figure 3. Algorithm for the management of patients with cirrhosis and bacterial infections. MDR, multi drug resistant; CA, community acquired. *Treatment as suggested for nosocomial infections (see Table 1). ${ }^{\dagger}$ See Table 1. ${ }^{\ddagger}$ Treatment should be prolonged for methicillin resistant Staphylococcus aureus bloodstream infections and other specific infections (e.g., endocarditis). Source control is mandatory (e.g., for abscesses). ${ }^{\text {STreatment }}$ of spontaneous bacterial peritonitis includes albumin expansion $1.5 \mathrm{~g} / \mathrm{kg}$ on day 1 and $1 \mathrm{gr} / \mathrm{kg}$ on day 3 .

group. Interestingly, circulatory and renal function improved only in the study group and a higher proportion of resolution of ACLF was found in albumin group than in control group. In spite of a strong pathophysiologic and clinical background, the available evidences suggest that the use of albumin cannot be routinely recommended for the treatment of non-SBP infections.

Increasing data have shown that patients with an acute decompensation of cirrhosis have frequently a relative adrenal insufficiency (RAl; inadequate glucocorticoid activity relative to illness), which is associated with the risk of developing AKI, sepsis, septic shock and ACLF. ${ }^{47-49}$ In patients with cirrhosis and septic shock, RAl was observed in $68-76 \%$ of patients..$^{50,51}$ The administration of low-dose steroids ( $50 \mathrm{mg} / 6$ hours IV) in this setting is associated with a higher rate of shock reversal. Controversial results exist on their impact on survival. ${ }^{50,51}$ Therefore, corticosteroids supplementation could be considered in patients with refractory septic shock, as occurs in the general population.

\section{PREVENTION OF BACTERIAL INFECTIONS}

Preventing bacterial infections is crucial in the management of patients with cirrhosis.

\section{Antibiotic prophylaxis}

Antibiotic prophylaxis is indicated in the following conditions: 1) patients with a previous episode of SBP; 2) patients with variceal bleeding; and 3) patients at high risk of SBP, i.e., patients with ascites protein level $<15 \mathrm{~g} / \mathrm{L}$ and at least one among the following: Child Pugh score $\geq 9$ with serum bilirubin $\geq 3 \mathrm{mg} / \mathrm{dL}$, serum creatinine $\geq 1.2 \mathrm{mg} / \mathrm{dL}$, blood urea nitrogen $\geq 25 \mathrm{mg} / \mathrm{dL}$ or serum sodium $\leq 130 \mathrm{mEq} / \mathrm{L}^{27}$ In patients at high risk for SBP, prophylaxis with norfloxacin $400 \mathrm{mg}$ per day has been associated with a significant reduction in the incidence of SBP and hepatorenal syndrome. ${ }^{52,53}$ Patients with variceal bleeding have a high risk of infections and in these patients antibiotic prophylaxis improve survival. ${ }^{27}$ A prophylactic treatment with Ceftriaxone $1 \mathrm{~g}$ per day for 7 days is significantly more effective than norfloxacin in preventing infections. ${ }^{54} \mathrm{After}$ the first episodes of SBP the risk of recurrence is almost $70 \%$ at 12 months. Prophylaxis with norfloxacin $400 \mathrm{mg}$ q.d. reduces the recurrence of SBP. ${ }^{55}$ Norfloxacin is not available in many countries and the use ciprofloxacin (500 $\mathrm{mg} /$ day) or trimethoprim-sulfamethoxazole (160/800 mg daily) are good alternatives. ${ }^{27,56}$ Rifaximin has been proposed as an alternative to norfloxacin in the prophylaxis of SBP in cirrhosis and it has been shown to reduce the risk of developing SBP in patients with hepatic encephalopathy. ${ }^{57}$ However, its real efficacy in prophylaxis 
Salvatore Piano, et al.

Management of infections in cirrhosis

is still to be determined.

\section{Non-antibiotic prophylaxis}

Since the use of antibiotic prophylaxis inevitably causes antibiotic resistance, non-antibiotic strategy would be highly desirable. The use of non-selective beta-blockers seems to reduce bacterial translocation and the occurrence of SBP in patients with cirrhosis. ${ }^{58,59}$ Albumin has been shown to restore immune dysfunction in patients with cirrhosis. ${ }^{60}$ Recently, albumin administration (40 g twice a week for 2 weeks followed by $40 \mathrm{~g} /$ week) showed to prevent the incidence of SBP and other infections in patients with uncomplicated ascites and refractory ascites and was associated with an improvement in survival. ${ }^{61,62}$ However, a randomized placebo-controlled study in patients with cirrhosis on liver transplant waiting list did not show a benefit with the use of albumin ${ }^{63}$ and future studies should confirm whether albumin treatment can prevent infections in cirrhosis.

\section{CONCLUSIONS AND FUTURE AREAS OF RE- SEARCH}

Bacterial infections represent a frequent complication with a very negative impact on survival in patients with cirrhosis. Early detection and effective treatment are fundamental to improve prognosis of these patients, as well as the prevention of AKI and ACLF. The current and increasing spread of MDR bacteria is especially alarming in patients with cirrhosis and represents the new challenge to be faced in the management of these patients.

Several unmet needs should be addressed in next future. As for the diagnosis, biomarkers for the early diagnosis of infections should be implemented as well as new fast strategies to identify infections caused by MDR bacteria. Microbial surveillance with nasal and rectal swab should be implemented to identify carriers of MDR bacteria and to reduce their spread with contact precautions. Carbapenem sparing strategies should be explored in the treatment of bacterial infections due to MDR bacteria. Non-antibiotic management for the prevention and treatment of organ failures should be developed. The bacterial infections risk should be better refined in inpatients and outpatients in order to identify those patients that can get the highest benefit by antimicrobial prophylaxis. Finally, non-antibiotic prophylactic strategies counteracting immune dysfunction and bacterial translocation should be investigated.

\section{Authors' contribution}

SP, MT, PA reviewed the literature and drafted the manuscript.

\section{Acknowledgements}

Salvatore Piano research activity has been supported by a EU Horizon 2020 Programme (Grant/Award Number H2020-SC12016-RTD), LIVERHOPE (Grant/Award Number 731875).

\section{Conflicts of Interest}

Salvatore Piano advises Mallinckrodt. Marta Tonon has nothing to disclose. Paolo Angeli advised Biovie, Grifols, Sequana Medical and received travel and conference grant by Boehringer.

\section{REFERENCES}

1. Jalan R, Fernandez J, Wiest R, Schnabl B, Moreau R, Angeli P, et al. Bacterial infections in cirrhosis: a position statement based on the EASL Special Conference 2013. J Hepatol 2014;60:1310-1324.

2. Albillos A, Lario M, Álvarez-Mon M. Cirrhosis-associated immune dysfunction: distinctive features and clinical relevance. J Hepatol 2014;61:1385-1396.

3. Clària J, Moreau R, Fenaille F, Amorós A, Junot C, Gronbaek H, et al. Orchestration of tryptophan-kynurenine pathway, acute decompensation, and acute-on-chronic liver failure in cirrhosis. Hepatology 2019;69:1686-1701.

4. Wiest $R$, Lawson M, Geuking M. Pathological bacterial translocation in liver cirrhosis. J Hepatol 2014;60:197-209.

5. Bajaj JS, Heuman DM, Hylemon PB, Sanyal AJ, White MB, Monteith $P$, et al. Altered profile of human gut microbiome is associated with cirrhosis and its complications. J Hepatol 2014;60:940-947.

6. Huelin P, Piano S, Solà E, Stanco M, Solé C, Moreira R, et al. Validation of a staging system for acute kidney injury in patients with cirrhosis and association with acute-on-chronic liver failure. Clin Gastroenterol Hepatol 2017;15:438-445.

7. Merli M, Lucidi C, Pentassuglio I, Giannelli V, Giusto M, Di Gregorio $V$, et al. Increased risk of cognitive impairment in cirrhotic patients with bacterial infections. J Hepatol 2013;59:243-250.

8. Moreau R, Jalan R, Gines P, Pavesi M, Angeli P, Cordoba J, et al. Acute-on-chronic liver failure is a distinct syndrome that develops in patients with acute decompensation of cirrhosis. Gastroenterology 2013;144:1426-1437.E9.

9. Arvaniti V, D'Amico G, Fede G, Manousou P, Tsochatzis E, Pleguezuelo $M$, et al. Infections in patients with cirrhosis increase mortality four-fold and should be used in determining prognosis. Gastroenterology 2010;139:1246-1256.E5.

10. Trebicka J, Fernandez J, Papp M, Caraceni P, Laleman W, Gambino 
C, et al. PREDICT identifies precipitating events associated with the clinical course of acutely decompensated cirrhosis. J Hepatol 2021;74:1097-1108.

11. Schmidt ML, Barritt AS, Orman ES, Hayashi PH. Decreasing mortality among patients hospitalized with cirrhosis in the United States from 2002 through 2010. Gastroenterology 2015;148:967-977.e2.

12. Fernández J, Bert F, Nicolas-Chanoine MH. The challenges of multidrug-resistance in hepatology. J Hepatol 2016;65:1043-1054.

13. Fernández J, Prado V, Trebicka J, Amoros A, Gustot T, Wiest R, et al. Multidrug-resistant bacterial infections in patients with decompensated cirrhosis and with acute-on-chronic liver failure in Europe. J Hepatol 2019;70:398-411.

14. Fasolato S, Angeli P, Dallagnese L, Maresio G, Zola E, Mazza E, et al. Renal failure and bacterial infections in patients with cirrhosis: epidemiology and clinical features. Hepatology 2007;45:223-229.

15. Piano S, Singh V, Caraceni P, Maiwall R, Alessandria C, Fernandez $J$, et al. Epidemiology and effects of bacterial infections in patients with cirrhosis worldwide. Gastroenterology 2019;156:1368-1380.e10.

16. Fernández J, Acevedo J, Castro M, Garcia O, de Lope CR, Roca D, et al. Prevalence and risk factors of infections by multiresistant bacteria in cirrhosis: a prospective study. Hepatology 2012;55:1551-1561.

17. Bartoletti M, Giannella M, Lewis R, Caraceni P, Tedeschi S, Paul M, et al. A prospective multicentre study of the epidemiology and outcomes of bloodstream infection in cirrhotic patients. Clin Microbiol Infect 2018;24:546.e1-546.e8.

18. Piano $S$, Bartoletti $M$, Tonon $M$, Baldassarre $M$, Chies $G$, Romano A, et al. Assessment of Sepsis-3 criteria and quick SOFA in patients with cirrhosis and bacterial infections. Gut 2018;67:1892-1899.

19. Merli M, Lucidi C, Di Gregorio V, Falcone M, Giannelli V, Lattanzi B, et al. The spread of multi drug resistant infections is leading to an increase in the empirical antibiotic treatment failure in cirrhosis: a prospective survey. PLoS One 2015;10:e0127448.

20. Tandon P, DeLisle A, Topal JE, Garcia-Tsao G. High prevalence of antibiotic-resistant bacterial infections among patients with cirrhosis at a US liver center. Clin Gastroenterol Hepatol 2012;10:1291-1298.

21. Bajaj JS, O'Leary JG, Reddy KR, Wong F, Olson JC, Subramanian RM, et al. Second infections independently increase mortality in hospitalized patients with cirrhosis: the North American consortium for the study of end-stage liver disease (NACSELD) experience. Hepatology 2012;56:2328-2335.

22. Ariza X, Castellote J, Lora-Tamayo J, Girbau A, Salord S, Rota R, et al. Risk factors for resistance to ceftriaxone and its impact on mortality in community, healthcare and nosocomial spontaneous bacterial peritonitis. J Hepatol 2012;56:825-832.

23. Cheong HS, Kang Cl, Lee JA, Moon SY, Joung MK, Chung DR, et al. Clinical significance and outcome of nosocomial acquisition of spontaneous bacterial peritonitis in patients with liver cirrhosis. Clin Infect Dis 2009:48:1230-1236.
24. Fernández J, Navasa M, Gómez J, Colmenero J, Vila J, Arroyo V, et al. Bacterial infections in cirrhosis: epidemiological changes with invasive procedures and norfloxacin prophylaxis. Hepatology 2002;35:140-148.

25. Reuken PA, Pletz MW, Baier M, Pfister W, Stallmach A, Bruns T. Emergence of spontaneous bacterial peritonitis due to enterococci - risk factors and outcome in a 12-year retrospective study. Aliment Pharmacol Ther 2012;35:1199-1208.

26. Piano S, Brocca A, Mareso S, Angeli P. Infections complicating cirrhosis. Liver Int 2018;38 Suppl 1:126-133.

27. European Association for the Study of the Liver. EASL clinical practice guidelines for the management of patients with decompensated cirrhosis. J Hepatol 2018;69:406-460.

28. Bajaj JS, O'Leary JG, Reddy KR, Wong F, Biggins SW, Patton H, et al. Survival in infection-related acute-on-chronic liver failure is defined by extrahepatic organ failures. Hepatology 2014;60:250-256.

29. Wong F, Piano S, Singh V, Bartoletti M, Maiwall R, Alessandria C, et al. Clinical features and evolution of bacterial infection-related acute-on-chronic liver failure. J Hepatol 2021;74:330-339.

30. Arroyo V, Moreau R, Jalan R. Acute-on-chronic liver failure. N Engl J Med 2020;382:2137-2145.

31. Fernández J, Acevedo J, Wiest R, Gustot T, Amoros A, Deulofeu $C$, et al. Bacterial and fungal infections in acute-on-chronic liver failure: prevalence, characteristics and impact on prognosis. Gut 2018:67:1870-1880.

32. Angeli P, Tonon M, Pilutti C, Morando F, Piano S. Sepsis-induced acute kidney injury in patients with cirrhosis. Hepatol Int 2016;10:115-123.

33. Piano S, Romano A, Di Pascoli M, Angeli P. Why and how to measure renal function in patients with liver disease. Liver Int 2017;37 Suppl 1:116-122.

34. Arabi YM, Dara SI, Memish Z, Al Abdulkareem A, Tamim HM, AlShirawi N, et al. Antimicrobial therapeutic determinants of outcomes from septic shock among patients with cirrhosis. Hepatology 2012;56:2305-2315.

35. Piano S, Fasolato S, Salinas F, Romano A, Tonon M, Morando F, et al. The empirical antibiotic treatment of nosocomial spontaneous bacterial peritonitis: results of a randomized, controlled clinical trial. Hepatology 2016;63:1299-1309.

36. Lutz P, Nischalke HD, Krämer B, Goeser F, Kaczmarek DJ, Schlabe $S$, et al. Antibiotic resistance in healthcare-related and nosocomial spontaneous bacterial peritonitis. Eur J Clin Invest 2017;47:44-52.

37. Kim SW, Yoon JS, Park J, Jung YJ, Lee JS, Song J, et al. Empirical treatment with carbapenem vs third-generation cephalosporin for treatment of spontaneous bacterial peritonitis. Clin Gastroenterol Hepatol 2021;19:976-986.

38. Merli M, Lucidi C, Di Gregorio V, Lattanzi B, Giannelli V, Giusto M, et al. An empirical broad spectrum antibiotic therapy in health-careassociated infections improves survival in patients with cirrhosis: a 
Salvatore Piano, et al.

Management of infections in cirrhosis

randomized trial. Hepatology 2016;63:1632-1639.

39. Bartoletti M, Giannella M, Lewis R, Tedeschi S, Verucchi G, Caraceni $P$, et al. Continuous infusion of beta-lactam antibiotics in cirrhotic patients with bloodstream infection: results from a prospective multicentre observational study. J Hepatol 2018;68:S44-S45.

40. Piano S, Morando F, Carretta G, Tonon M, Vettore E, Rosi S, et al. Predictors of early readmission in patients with cirrhosis after the resolution of bacterial infections. Am J Gastroenterol 2017;112:15751583.

41. Runyon BA, Mchutchison JG, Antillon MR, Akriviadis EA, Montano $A A$. Short-course versus long-course antibiotic treatment of spontaneous bacterial peritonitis. A randomized controlled study of 100 patients. Gastroenterology 1991;100:1737-1742.

42. Sort P, Navasa M, Arroyo V, Aldeguer X, Planas R, Ruiz-del-Arbol L, et al. Effect of intravenous albumin on renal impairment and mortality in patients with cirrhosis and spontaneous bacterial peritonitis. N Engl J Med 1999;341:403-409.

43. Bernardi M, Angeli P, Claria J, Moreau R, Gines P, Jalan R, et al. Albumin in decompensated cirrhosis: new concepts and perspectives. Gut 2020;69:1127-1138.

44. Guevara M, Terra C, Nazar A, Solà E, Fernández J, Pavesi M, et al. Albumin for bacterial infections other than spontaneous bacterial peritonitis in cirrhosis. A randomized, controlled study. J Hepatol 2012;57:759-765.

45. Thévenot $T$, Bureau C, Oberti F, Anty R, Louvet $A$, Plessier $A$, et al. Effect of albumin in cirrhotic patients with infection other than spontaneous bacterial peritonitis. A randomized trial. J Hepatol 2015;62:822-830.

46. Fernández J, Angeli P, Trebicka J, Merli M, Gustot T, Alessandria C, et al. Efficacy of albumin treatment for patients with cirrhosis and infections unrelated to spontaneous bacterial peritonitis. Clin Gastroenterol Hepatol 2020;18:963-973.e14.

47. Acevedo J, Fernández J, Prado V, Silva A, Castro M, Pavesi M, et al. Relative adrenal insufficiency in decompensated cirrhosis: relationship to short-term risk of severe sepsis, hepatorenal syndrome, and death. Hepatology 2013;58:1757-1765.

48. Piano S, Favaretto E, Tonon M, Antonelli G, Brocca A, Sticca A, et al. Including relative adrenal insufficiency in definition and classification of acute-on-chronic liver failure. Clin Gastroenterol Hepatol 2020;18:1188-1196.e3.

49. Jang JY, Kim TY, Sohn JH, Lee TH, Jeong SW, Park EJ, et al. Relative adrenal insufficiency in chronic liver disease: its prevalence and effects on long-term mortality. Aliment Pharmacol Ther 2014;40:819826.

50. Fernández J, Escorsell A, Zabalza M, Felipe V, Navasa M, Mas A, et al. Adrenal insufficiency in patients with cirrhosis and septic shock: effect of treatment with hydrocortisone on survival. Hepatology 2006;44:1288-1295.
51. Arabi YM, Aljumah A, Dabbagh 0, Tamim HM, Rishu AH, AlAbdulkareem $A$, et al. Low-dose hydrocortisone in patients with cirrhosis and septic shock: a randomized controlled trial. CMAJ 2010;182:1971-1977.

52. Fernández J, Navasa M, Planas R, Montoliu S, Monfort D, Soriano G, et al. Primary prophylaxis of spontaneous bacterial peritonitis delays hepatorenal syndrome and improves survival in cirrhosis. Gastroenterology 2007;133:818-824.

53. Moreau R, Elkrief L, Bureau C, Perarnau JM, Thévenot T, Saliba F, et al. Effects of long-term norfloxacin therapy in patients with advanced cirrhosis. Gastroenterology 2018;155:1816-1827.e9.

54. Fernández J, Ruiz del Arbol L, Gómez C, Durandez R, Serradilla R, Guarner $C$, et al. Norfloxacin vs ceftriaxone in the prophylaxis of infections in patients with advanced cirrhosis and hemorrhage. Gastroenterology 2006;131:1049-1056.

55. Ginés P, Rimola A, Planas R, Vargas V, Marco F, Almela M, et al. Norfloxacin prevents spontaneous bacterial peritonitis recurrence in cirrhosis: results of a double-blind, placebo-controlled trial. Hepatology 1990;12(4 Pt 1):716-724.

56. Lontos S, Shelton E, Angus PW, Vaughan R, Roberts SK, Gordon A, et al. A randomized controlled study of trimethoprim-sulfamethoxazole versus norfloxacin for the prevention of infection in cirrhotic patients. J Dig Dis 2014;15:260-267.

57. Kang SH, Lee YB, Lee JH, Nam JY, Chang Y, Cho H, et al. Rifaximin treatment is associated with reduced risk of cirrhotic complications and prolonged overall survival in patients experiencing hepatic encephalopathy. Aliment Pharmacol Ther 2017;46:845-855.

58. Reiberger T, Ferlitsch A, Payer BA, Mandorfer M, Heinisch BB, Hayden $\mathrm{H}$, et al. Non-selective betablocker therapy decreases intestinal permeability and serum levels of LBP and IL- 6 in patients with cirrhosis. J Hepatol 2013;58:911-921.

59. Senzolo M, Cholongitas E, Burra P, Leandro G, Thalheimer U, Patch D, et al. $\beta$-blockers protect against spontaneous bacterial peritonitis in cirrhotic patients: a meta-analysis. Liver Int 2009;29:1189-1193.

60. O'Brien AJ, Fullerton JN, Massey KA, Auld G, Sewell G, James S, et al. Immunosuppression in acutely decompensated cirrhosis is mediated by prostaglandin E2. Nat Med 2014;20:518-523.

61. Caraceni P, Riggio O, Angeli P, Alessandria C, Neri S, Foschi FG, et al. Long-term albumin administration in decompensated cirrhosis (ANSWER): an open-label randomised trial. Lancet 2018;391:24172429.

62. Di Pascoli M, Fasolato S, Piano S, Bolognesi M, Angeli P. Long-term administration of human albumin improves survival in patients with cirrhosis and refractory ascites. Liver Int 2019;39:98-105.

63. Solà E, Solé C, Simón-Talero M, Martín-Llahí M, Castellote J, GarciaMartínez $R$, et al. Midodrine and albumin for prevention of complications in patients with cirrhosis awaiting liver transplantation. A randomized placebo-controlled trial. J Hepatol 2018;69:1250-1259. 